
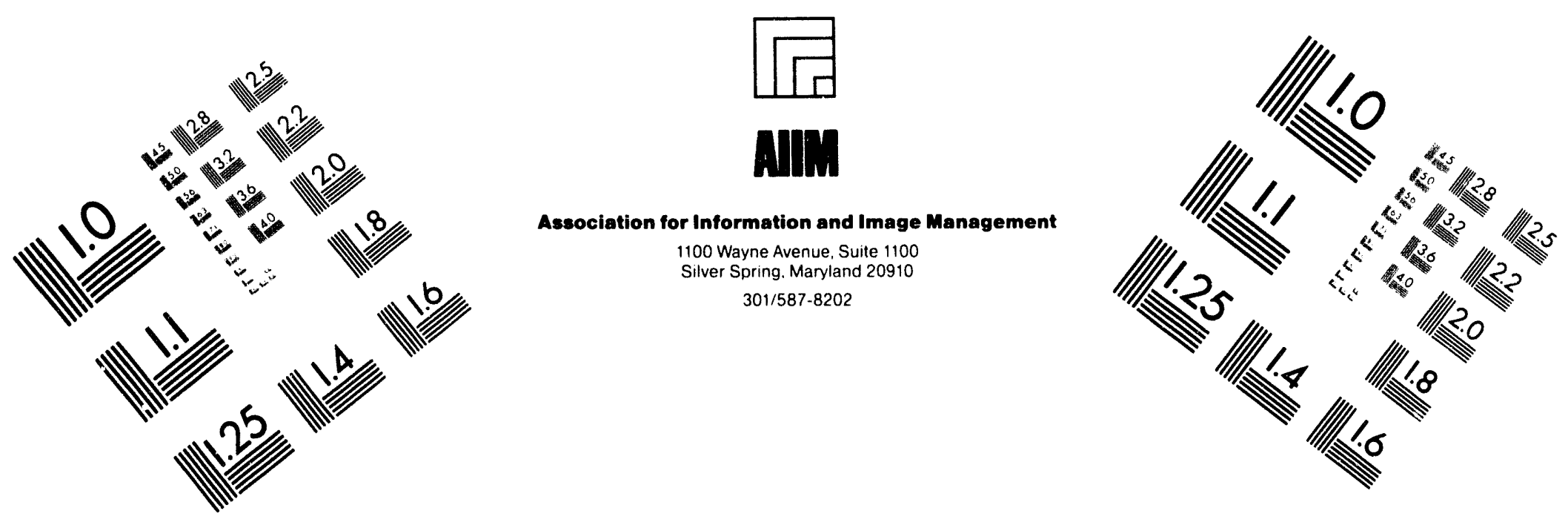

\title{
Centimeter
}

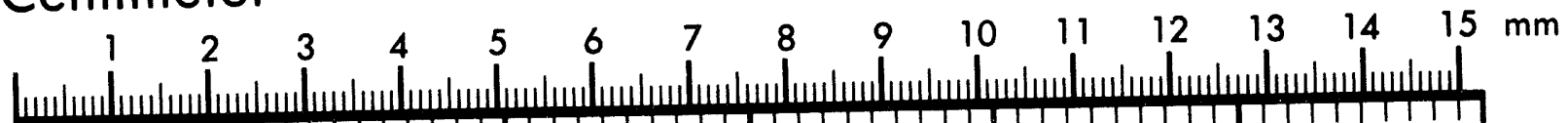

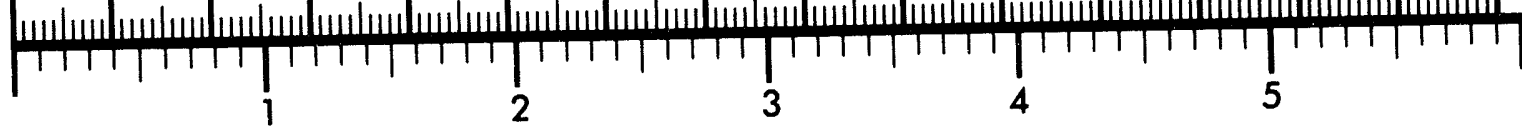
Inches
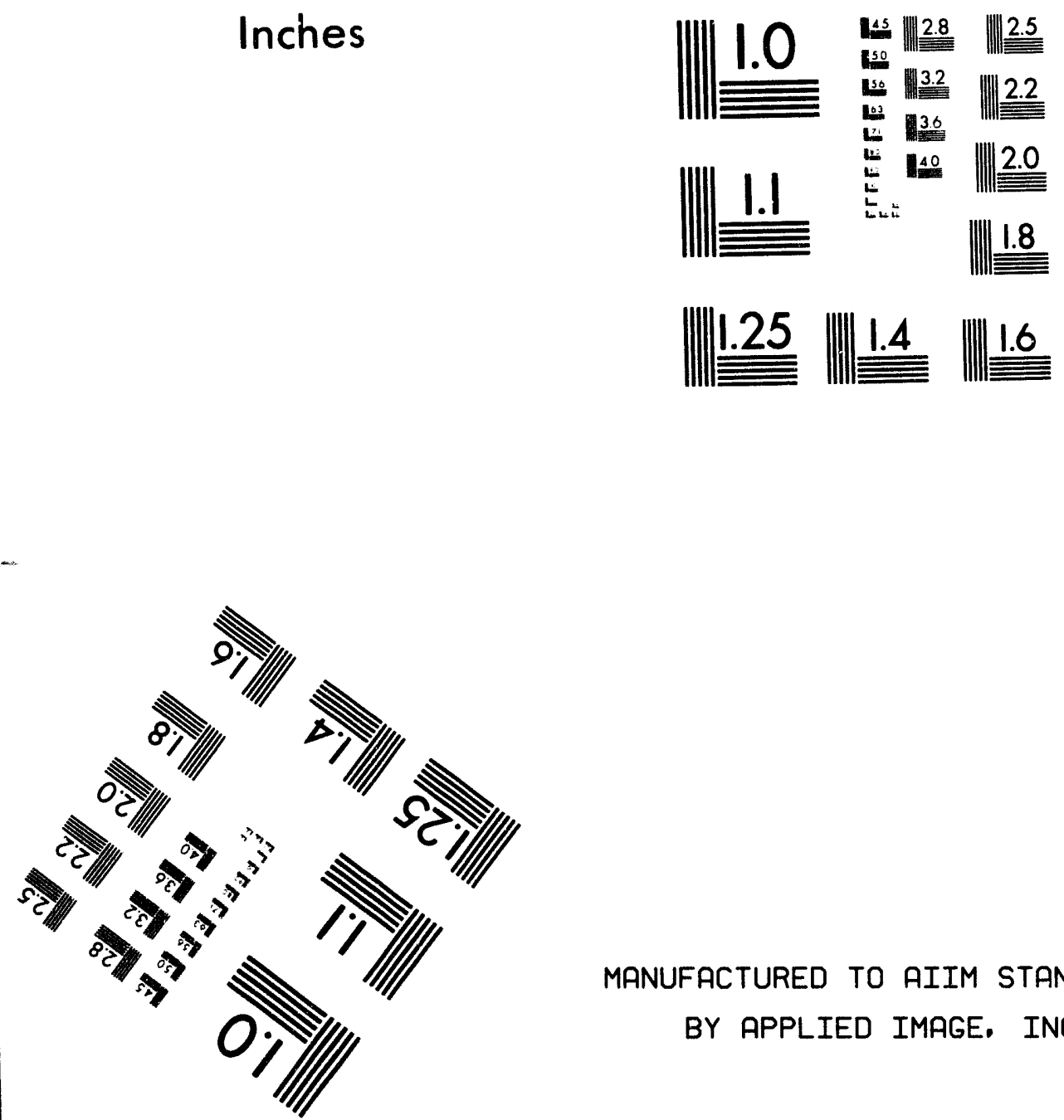

MANUFACTURED TO AIIM STANDARDS

BY APPLIED IMAGE, INC.

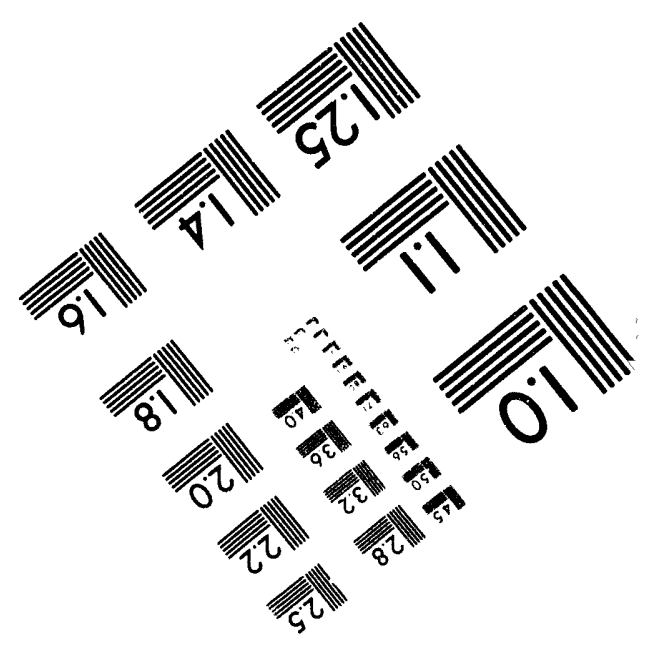



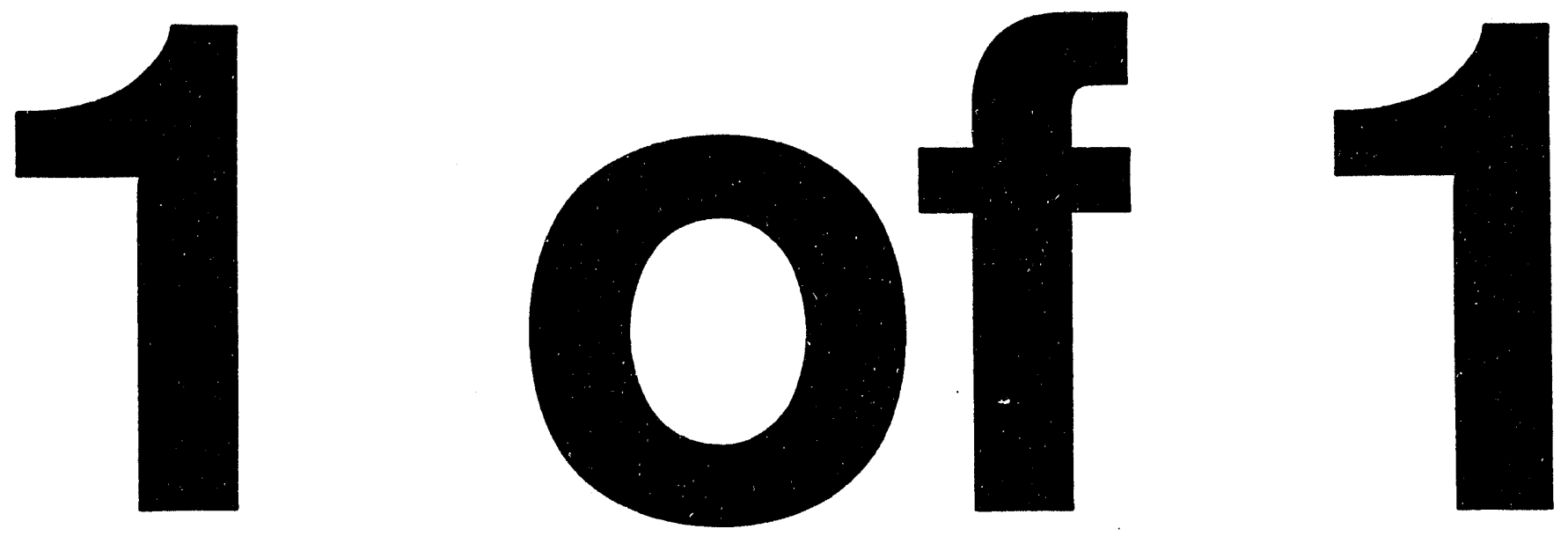


\title{
DECLASSIFIED
}

\author{
$A R H-R-5 I$
}

\section{STRONTIUM ISOTOPE RATIOS}

Harold H. Van Tuyl
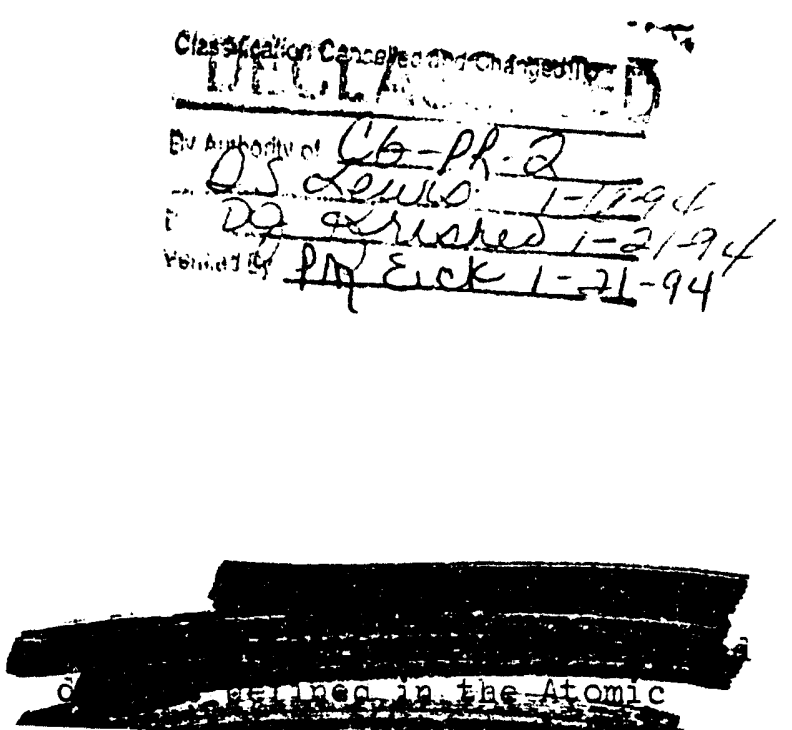

\section{DISCLAIMER}

This report was prepared as an account of work sponsored by an agency of the United States Government. Neither the United States Government nor any agency thereof, nor any of their employees, makes any warranty, express or implied, or assumes any legal liability or responsibility for the accuracy, completeness, or usefulness of any information, apparatus, product, or process disclosed, or represents that its use would not infringe privately owned rights. Reference herein to any specific commercial product, process, or service by trade name, trademark, mendation, or favoring by does not necessarily constitute or imply its endorsement, recommendation, or favoring by the United States Government or any agency thereof. The views United States Government or any agency thereof.
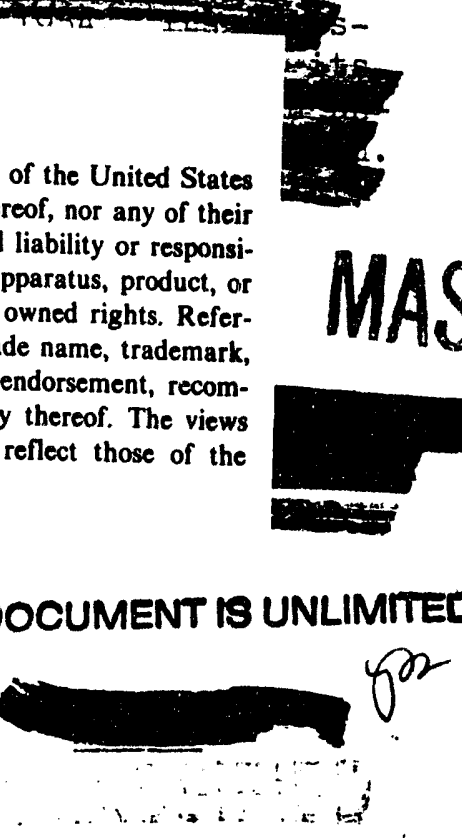
December 1, 1969

Mr. A. E. Barber

Atlantic Richfield Hanford Company

Federal Building

$825 \mathrm{Jadwin}$

Richland, Washington

99352

Dear Mr. Barber:

\section{Strontium Isotope Ratios}

As you requested, I have taken a brief look at p. 14 of MND-3062-2 to see what information can be derived from it. The basic information given is ${ }^{9}{ }^{\circ} \mathrm{Sr} / \mathrm{Sr}$ total and ${ }^{89} \mathrm{Sr} /{ }^{90} \mathrm{Sr}$. The ratio of ${ }^{\circ} \mathrm{Sr}$ to total $\mathrm{Sr}$ is not affected appreciably by changes in reactor power level, fuel composition, or total exposure. Changes after reactor discharge are about one percent per year. The major uncertainty in this ratio is the amount of extraneous strontium introduced during chemical processing. It is apparently impossible for any believable estimate of power level or total exposure to be derived from the ${ }^{\circ} \mathrm{Sr} / \mathrm{Sr}$ total ratio.

The ratio of ${ }^{89} \mathrm{Sr} /{ }^{9} \mathrm{Sr}$ is not at all constant, but varies with time in the reactor and with time since reactor discharge. The basic equation for the activity, $A$, of a primary fission product is

$$
A=R Y\left(1-e^{-\lambda t_{1}}\right) e^{-\lambda t_{2}}
$$

where $R$ is the fission rate, $Y$ is the fission yield, $t_{1}$ and $t_{2}$ are the irradiation and cooling times respectively, and $\lambda$ is the decay constant of the fission product. The activity ratio of two fission products is

$$
A a / A b=\frac{Y a}{Y b}\left(\frac{1-e^{-\lambda_{a} t_{1}}}{1-e^{-\lambda_{b} t_{1}}}\right) e^{-\left(\lambda_{a}-\lambda_{b}\right) t_{2}}
$$




\section{B ATTELLE NORTHWEST}

Mr. A. E. Barber

December 1, 1969

This ratio is dependent on both $t_{1}$ and $t_{2}$, but it is not possible to distinguish relative values for $t_{1}$ and $t_{2}$ with only a single fission product ratio. In MND 3062-2 the ratio is given at a specific time after Purex processing. Other sources can provide the average cooling time before Purex processing, so that $t_{2}$ can be derived from the report. Solution for $t_{1}$, the time in the reactor, is then straightforward. I do not know the classification of this irradiation time. The data in the document are not precise, and my attempts at deriving irradiation times did not yield values close to the real values for Hanford reactors. However, I have not determined the probable accuracy of the irradiation time derived in this way. Neither reactor power level nor integrated exposure can be derived from the ${ }^{89} \mathrm{Sr} /{ }^{90} \mathrm{Sr}$ ratio.

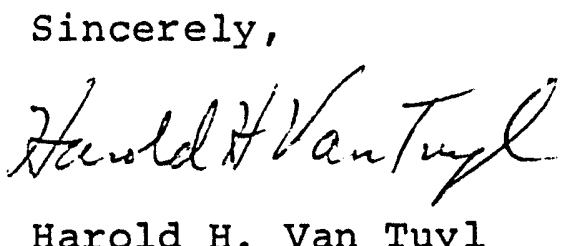

$\mathrm{HHVT}: \mathrm{mfg}$ 

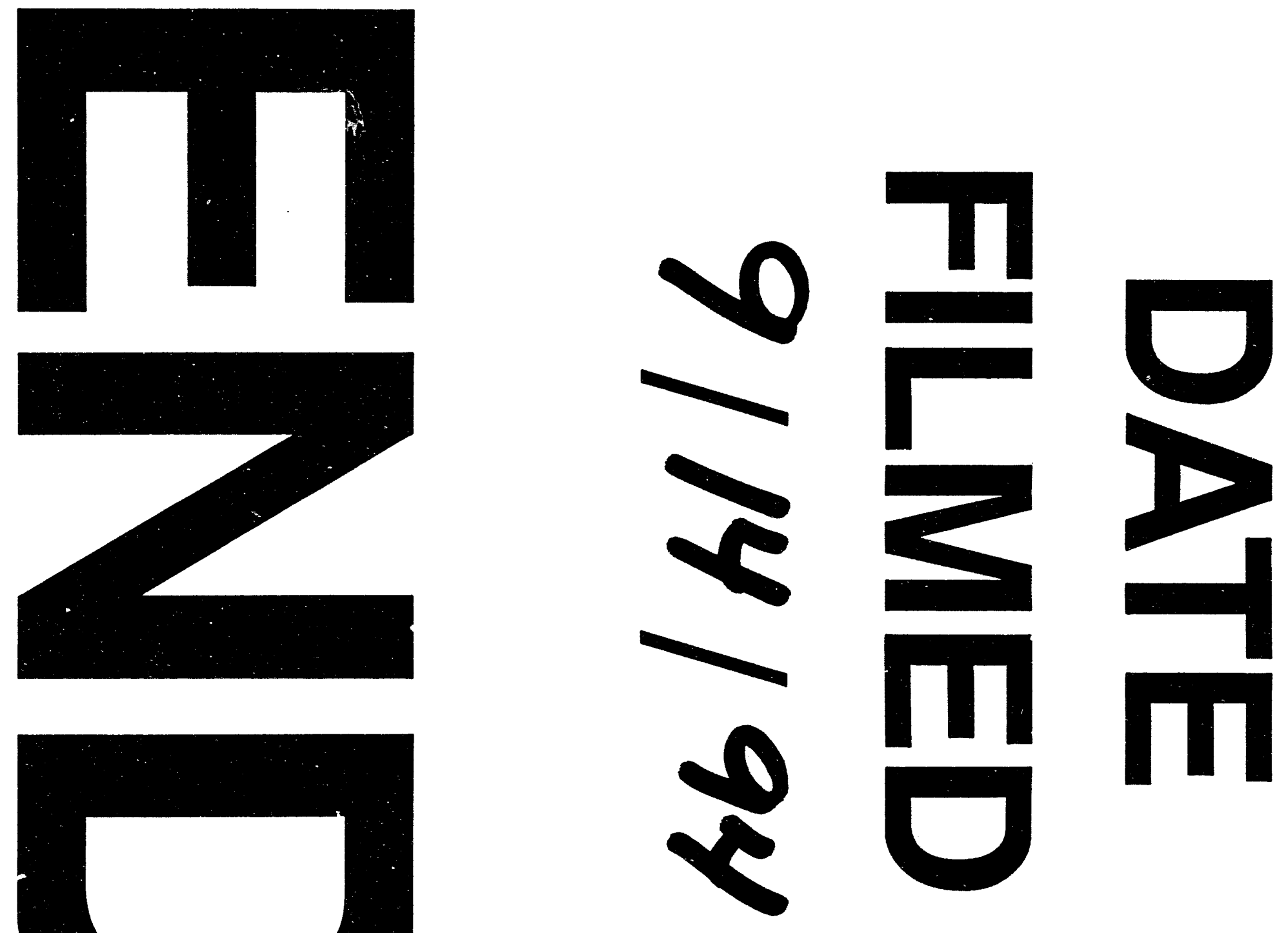

․ㅜ

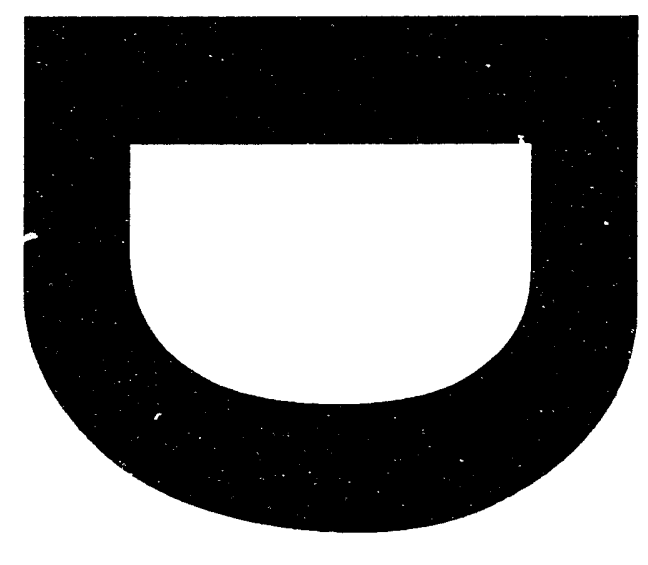


